ward a consultant should be posted to decide on priorities, and he should not leave to go to theatre: triage is a continuous process of assessing changes in the condition of the patients already admitted as well as examining new arrivals with serious injuries who may need to jump the queue. This ward must be given extra equipment at an early stage, so that, for example, giving-sets and drip stands can be ready at each bed.

Primary management should be decided by the consultant at the reception area and he should first identify dead victims and have them moved. Many injuries will be suitable for treatment in the accident department by residents and students, with one or more registrars in charge. Severely injured patients should be given blood or dextran here before being moved to the admission ward or directly to theatre. Full use should be made of inflatable transparent splints for open limb fractures-it is bad practice to remove dressings to inspect wounds before the patient is in theatre.

Blast injuries of the lungs should bypass the admission ward and go straight to the intensive care unit, where the anaesthetist in charge should already be present. These patients may need intermittent or continuous positivepressure ventilation, but they do not usually need tracheostomy at an early stage. ${ }^{2}$ Blood gas levels should be monitored and attention paid to the results of the damage caused to the lung tissues by the rapid pressure changes at the time of the blast.

Burns are of flash type in small bomb explosions, and though they may be extensive are very superficial. When much of the body surface is affected and especially when the face and eyelids are burnt, patients are probably best managed in a burns unit. Blast may cause damage to eardrums but immediate treatment is not vital. Penetrating injuries of the thorax and abdomen must take precedence over other injuries and should be in the theatre as soon as possible. Penetrating injuries of the eye need early attention by an eye surgeon, but fractures and skeletal injuries can safely wait their turn unless complicated by major arterial bleeding. ${ }^{4}$

1 Caro, D., and Irving, M., Lancet, 1973, 1, 1433.

2 Ashbaugh, D. G., et al., Fournal of Thoracic and Cardiovascular Surgery, $1969,57,31$.

${ }^{3}$ McCaughey, W., Coppel, D. L., and Dundee, J. W., Anaesthesia, 1973,

4 Waddell, J. P., and Lenczner, E. M., Injury, 1974, 6, 28.

\section{Lassa Fever}

Lassa fever ${ }^{1}$ continues to present problems to physicians in Britain and other countries, and may well present still greater problems in the future. Since the initial outbreak at Lassa, North Eastern Nigeria, in 1969 there have been other outbreaks near Jos in Northern Nigeria and in Liberia. After an outbreak in Sierra Leone in 1972, a signal case of which was reported in the B.M.F., ${ }^{2}$ there were more cases in Eastern Nigeria which received much publicity in the lay press and in which a doctor died. This month another doctor from Nigeria has died in London with a suspected diagnosis of Lassa fever. ${ }^{3}$ It is probable that the infection has accounted for some of the fatal cases of pyrexia of undetermined origin which for years have sporadically appeared in West Africa. Examination of sera collected for study of the epidemiology of trypanosomiasis and other diseases has shown that some may contain Lassa antibodies, thus indicating that the disease is more widespread than the known outbreaks would suggest. Any patient who presents with a pyrexia of undetermined origin and who has been in West Africa during the preceding 20 days should be suspected as possibly suffering from this infection.
In view of the importance of the problems presented by Lassa fever, in May 1974 the World Health Organisation convened a meeting of a group of virologists and public health officers to study the situation and assess current knowledge. A diagnosis of Lassa fever should especially be considered in patients with prostration more severe than the degree of fever might otherwise suggest, though benign febrile cases are known. In severe forms the onset is often insiduous, and during the first week the illness may resemble septicaemia or typhoid fever. A sore throat, vomiting, and abdominal and chest pains are common. During the second week the patient either becomes convalescent or his condition deteriorates; toxic symptoms become worse and vascular features may be superadded. Serous effusions, facial oedema, haemorrhagic lesions, disturbance of the central nervous system, and profound shock may supervene. The case fatality rate among such patients may be between 30 and $50 \%$.

Confirmation of diagnosis may be made by growth of the virus in tissue culture and also by use of a complement fixation test. This test, however, is rarely positive before the 14th day of the illness. Cultural tests are currently carried out only at the Communicable Disease Centre, Atlanta, U.S.A. The only specific treatment likely to be of value is the administration of plasma obtained from a convalescent patient-and plasma of this kind is in very short supply. A small stock is held at the Hospital for Tropical Diseases, London. Treatment otherwise consists in combating shock and in maintaining proper fluid balance.

The infection is caused by a virus which has been placed in a new group named arenoviruses. It is related to the Tacaribe complex and to the viruses causing lymphocytic choriomeningitis. Mastomys natalensis, a multimammate rat widespread in Africa, is known to be an animal reservoir of the virus, and primary human cases probably result from contamination of foodstuffs with rodent urine. The infection is marked by a very high rate of transmission to contacts of patients. Transmission may occur through contact with excreta, such as urine, faeces, vomit, or saliva, through droplets and aerosols, and particularly through wounds contaminated with blood or secretions from an infected patient. There are now a number of records of infection having occurred through accidents such as pricking a finger with a needle being used in an attempt to administer intravenous fluid. A fatal infection is known to have occurred from a cut received in carrying out a necropsy on a patient who had died from the disease. There is some evidence that primary human cases are more highly contagious for contacts than are secondary cases.

Very strict isolation of known or suspected patients should be enforced, with special precautions aimed at minimizing possible spread of the infection to others in hospital. Details of such recommended precautions have been issued by the World Health Organization. ${ }^{4}$ Known contacts should be kept under medical surveillance for a period of at least 17 days, and any who develop pyrexia during such a period should be isolated as suspected cases of Lassa fever. Transmission of virus to others is very unlikely to occur from those who have not developed fever. On epidemiological grounds the World Health Organization recommends that patients suspected of having Lassa fever should not be moved out of the endemic area, but if for medical reasons the patient must be moved to another country then common sense precautions should be taken to minimize the risks of spreading the virus. In aircraft the main risk is by aerosol transmission and the use of available apparatus can diminish this greatly. For travellers and persons in Britain the greatest risk is not 
from those known to have infection but from those travelling or coming to hospital in the earlier phases of the infection, when they may merely feel unwell and have some fever, possibly of slight degree.

1 British Medical fournal, 1972, 4, 253.

2 Woodruff, A. W., et al., British Medical fournal, 1973, 3, 616.

3 The Times, 14 January, 1975.

4 W.H.O. Weekly Epidemiological Record, 1974, 49, 341.

\section{Back from the Brink}

The Government has finally recognized that its collision course with consultants could cause irreparable damage to the Health Service. Last week in Parliament (18 January, p. 159), Mrs. Castle seemed to be stepping back from the brink of confrontation and a subsequent letter to the B.M.A.'s Secretary strengthened this impression (p. 224). After discussing these latest developments the Central Committee for Hospital Medical Services (p. 225) decided to accept her suggestion for talks about talks. But until she gives evidence of her good intention senior hospital doctors have been asked to continue working to their contracts.

To unite in indignation over ill-considered Government policy was relatively easy-and, as reports from the country (including an unprecedented letter on p. 226 from London teaching hospital staff) show, this dispute has brought consultants together as never before. But it is less easy to agree on the next step now that the negotiating impasse has apparently been broken. Before deciding on solutions, however, consultants should remember why they are facing the Government in anger.

Most doctors whole-heartedly support the concept of the N.H.S. and wish it to continue-though some will argue that its present troubles were inherent. Certainly the country's persisting economic weakness has steadily undermined the staffs' ability to maintain the delicate balance between resources and demands. As Sir Rodney Smith, President of the Royal College of Surgeons, writes on p. 209, "Extreme underfinancing" and the "catastrophic decline in morale among all manning the N.H.S." are endangering patient care.

The catalogue of woe has been made tedious by repetition: more patients and more work-contrasted with a lack of junior staff, of nurses and of paramedical staff, of equipment, and, all too often, of imagination. Some executive actions are almost beyond belief, as doctors in Leeds will confirm where the Womens' Hospital was demolished before a badly needed replacement was available. Now the capital expenditure cuts have meant no replacement and the "facilities for gynaecological patients are worse than they were in 1948."1 Such incidents drive doctors to despair, and when to their professional worries are added personal financial stresses their tolerance snaps.

The widespread dissatisfaction over the past few years led to the profession trying to negotiate a contract for consultants that would set a limit on the ever-rising work load and provide an adequate reward. After two years little progress had been made with the Health Departments at official level. Discussions were finally lifted to Ministerial level with Dr. David Owen chairing a working party charged with finding a quick solution. Advances were made until the Government's blatantly ideological approach to the peripheral issue of private beds disrupted the proceedings.

Annoyed though doctors were, they restarted the talks because a solution to the contract difficulties was urgent. But when before Christmas Mrs. Castle presented her Government's final proposals the content of the package and the manner of its delivery so infuriated the consultants' leaders that they advised their colleagues to work to contract.

The propaganda battle that followed has scarcely enlightened the issues at stake, which are defined in the letter from the President of the R.C.S. Nevertheless, the Government's December package has now been withdrawn and presumably consultants are back where they were. But time is short and the over-riding aim, as inflation worsens, must be to get consultants, particularly the younger ones, a substantial increase in their pay. To negotiate and price a new contract would mean an unacceptable delay so that the C.C.H.M.S. has decided to press ahead with evidence for the April review based on the existing contract. If it is possible in the time some easily made improvements to the contract (for instance, payments for night calls) would be sought as well. This is a pragmatic course that should appeal to most consultants, but the C.C.H.M.S. is rightly wary of Mrs. Castle's suggestion to submit in February a "general outline of evidence on the pricing of a new contract" for fear of prejudicing a substantial award in April. But what of the future ? Have the sanctions and their attendant tribulation been to no avail ?

The answer is No. The Government now knows the consultants' strength and their opposition to a whole-time service. The public has had another stark demonstration of the Health Service's weaknesses. Finally, consultants have been reminded how rewarding an occupation medicine can be when practised at a measured pace. The profession has also been warned of the use which a Government could make of a closed contract.

Inevitably the dispute has revealed more clearly differences of opinion among consultants but even these can be used to good effect. There has been plenty of opportunity in the past two years or so to discuss the B.M.A.'s 10-session contract proposals, which were endorsed by the National Conference of Hospital Staffs in $1972 .{ }^{4}$ The events of the last month or so have not suddenly rendered its principles obsolete. Nevertheless, no doubt Dr. C. E. Astley, Dr. E. B. Lewis, and their colleagues can use the recent experiences and the volume of comment from doctors to improve the proposals. If Mrs. Castle demonstrates her good faith in the forthcoming exploratory talks and sanctions are withdrawn negotiations can resume. But consultants are impatient for results. This time the Government cannot afford to let the talks fail for the whole future of the N.H.S. is at stake.

\footnotetext{
1 Yorkshire Post, 13 January, p.80.
2 British Medical fournal Supplement, 1972, 3, 60.
} 